\title{
Stepped Spillways: Theoretical, Experimental and Numerical Studies
}

\author{
André Luiz Andrade Simões, Harry Edmar Schulz, \\ Raquel Jahara Lobosco and Rodrigo de Melo Porto \\ University of São Paulo \\ Brazil
}

\section{Introduction}

Flows on stepped spillways have been widely studied in various research institutions motivated by the attractive low costs related to the dam construction using roller-compacted concrete and the high energy dissipations that are produced by such structures. This is a very rich field of study for researchers of Fluid Mechanics and Hydraulics, because of the complex flow characteristics, including turbulence, gas exchange derived from the twophase flow (air/water), cavitation, among other aspects. The most common type of flow in spillways is known as skimming flow and consists of: (1) main flow (with preferential direction imposed by the slope of the channel), (2) secondary flows of large eddies formed between steps and (3) biphasic flow, due to the mixture of air and water. The details of the three mentioned standards may vary depending on the size of the steps, the geometric conditions of entry into the canal, the channel length in the steps region and the flow rates. The second type of flow that was highlighted in the literature is called nappe flow. It occurs for specific conditions such as lower flows (relative to skimming flow) and long steps in relation to their height. In the region between these two "extreme" flows, a "transition flow" between nappe and skimming flows is also defined. Depending on the details that are relevant for each study, each of the three abovementioned types of flow may be still subdivided in more sub-types, which are mentioned but not detailed in the present chapter. Figure 1 is a sketch of the general appearance of the three mentioned flow regimes.
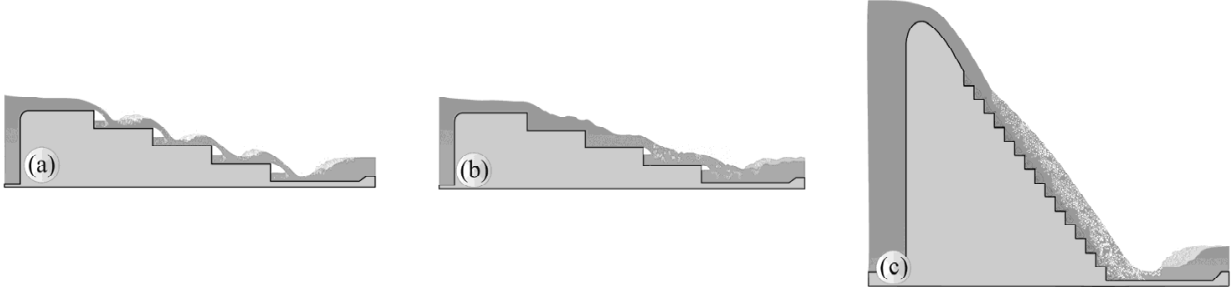

Fig. 1. Flow patterns on stepped chutes: (a) Nappe-flow, (b) transition flow and (c) skimming flow. 
The introductory considerations made in the first paragraph shows that complexities arise when quantifying such flows, and that specific or general contributions, involving different points of view, are of great importance for the advances in this field. This chapter aims to provide a brief general review of the subject and some results of experimental, numerical and theoretical studies generated at the School of Engineering of Sao Carlos - University of São Paulo, Brazil.

\section{A brief introduction and review of stepped chutes and spillways}

In this section we present some key themes, chosen accordingly to the studies described in the next sections. Additional sources, useful to complement the text, are cited along the explanations.

\subsection{Flow regimes}

It is interesting to observe that flows along stepped chutes have also interested a relevant person in the human history like Leonardo da Vinci. Figure 2a shows a well-known da Vinci's sketch (a mirror image), in which a nappe-flow is represented, with its successive falls. We cannot affirm that the sketching of such flow had scientific or aesthetic purposes, but it is curious that it attracted da Vinci's attention. Considering the same geometry outlined by the artist, if we increase the flow rate the "successive falls pattern" changes to a flow having a main channel in the longitudinal direction and secondary currents in the "cavities" formed by the steps, that is, the skimming flow mentioned in the introduction. Figure $2 b$ shows a drawing from the book Hydraulica of Johann Bernoulli, which illustrates the formation of large eddies due to the passage of the flow along step-formed discontinuities.

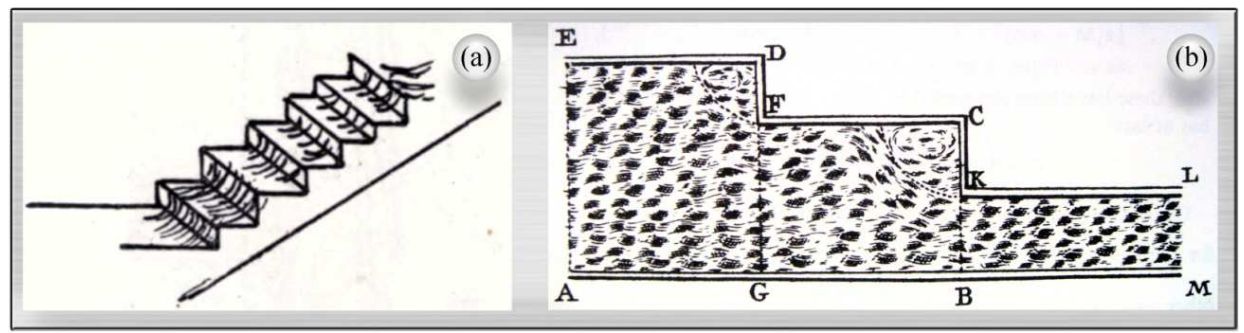

Fig. 2. Historical drawings related to the fields of turbulent flows in channels and stepped spillways: (a) Sketch attributed to Leonardo da Vinci (Richter, 1883, p.236) (mirror image), (b) Sketch presented in the book of Johann Bernoulli (Bernoulli, 1743, p.368).

The studies of Horner (1969), Rajaratnam (1990), Diez-Cascon et al. (1991), among others, presented the abovementioned patterns as two flow "regimes" for stepped chutes. For specific "intermediate conditions" that do not fit these two regimes, the transition flow was then defined (Ohtsu \& Yasuda, 1997). Chanson (2002) exposed an interesting sub-division of the three regimes. The nappe flow regime is divided into three sub-types, characterized by the formation or absence of hydraulic jumps on the bed of the stairs. The skimming flow regime is sub-divided considering the geometry of the steps and the flow conditions that lead to different configurations of the flow fields near the steps. Even the transition flow regime may be divided into sub-types, as can be found in the study of Carosi \& Chanson (2006). 
Ohtsu et al. (2004) studied stepped spillways with inclined floors, presenting experimental results for angles of inclination of the chute between 5.7 and 55० For angles between 19 and $55^{\circ}$ it was observed that the profile of the free surface in the region of uniform flow is independent of the ratio between the step height (s) and the critical depth $\left(h_{c}\right)$, that is, $s / h_{c}$, and that the free surface slope practically equals the slope of the pseudo-bottom. This subsystem was named "Profile Type A". For angles between 5.7 and 19, the unobstructed flow slide is not always parallel to the pseudo-bottom, and the Profile Type A is formed only for small values of $s / h_{c}$. For large values of $s / h_{c}$, the authors explain that the profile of the free surface is replaced by varying depths along a step. The skimming flow becomes, in part, parallel to the floor, and this sub-system was named "Profile Type B".

Researchers like Essery \& Horner (1978), Sorensen (1985), Rajaratnam (1990) performed experimental and theoretical studies and presented ways to identify nappe flows and skimming flows. Using results of recent studies, Simões (2011) presented the graph of Figure $3 a$, which contains curves relating the dimensionless $s / h_{c}$ and $s / 1$ proposed by different authors. Figure $3 \mathrm{~b}$ represents a global view of Figure $3 \mathrm{a}$, and shows that the different propositions of the literature may be grouped around two main curves (or lines), dividing the graph in four main areas (gray and white areas in Fig 3a). The boundaries between these four areas are presented as smooth transition regions (light brown in Fig 3b), corresponding to the region which covers the positions of the curves proposed by the different authors.

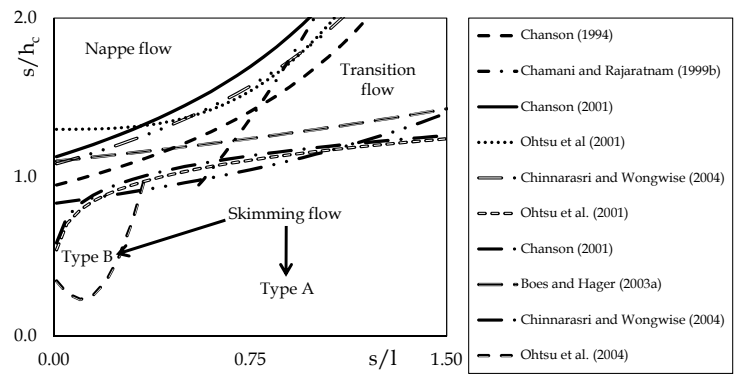

(a)

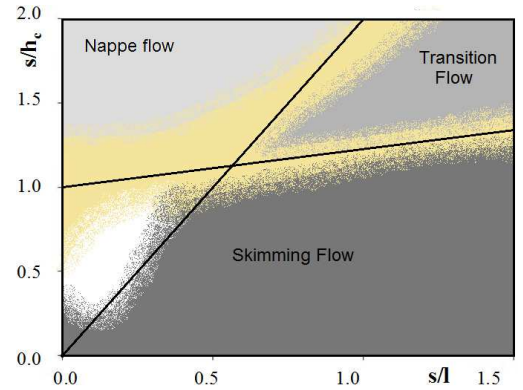

(b)

Fig. 3. Criteria for determining the types of flow: (a) curves of different authors (cited in the legend) and (b) analysis of the four main areas (white and gray) and the boundary regions (light brown) between the main areas (The lines are: $\mathrm{s} / \mathrm{h}_{\mathrm{c}}=2 \mathrm{~s} / \mathrm{l} ; \mathrm{s} / \mathrm{h}_{\mathrm{c}}=0.233 \mathrm{~s} / 1+1$ ).

\subsection{Skimming flow}

\subsubsection{Energy dissipation}

The energy dissipation of flows along stepped spillways is one of the most important characteristics of these structures. For this reason, several researchers have endeavored to provide equations and charts to allow predictions of the energy dissipation and the residual energy at the toe of stepped spillways and channels. Different studies were performed in different institutions around the world, representing the flows and the related phenomena from different points of view, for example, using the Darcy-Weisbach or the Manning equations, furnishing algebraic equations fitted to experimental data, presenting experimental points by means of graphs, or simulating results using different numerical schemes. 


\section{Darcy-Weisbach resistance function ("friction factor")}

The Darcy-Weisbach resistance function has been widely adopted in studies of stepped spillways. It can be obtained following arguments based on physical arguments or based on a combination of experimental information and theoretical principles. In the first case, dimensional analysis is used together with empirical knowledge about the energy evolution along the flow. In the second case, the principle of conservation of momentum is used together with experimental information about the averaged shear stress on solid surfaces. Of course, the result is the same following both points of view. The dimensional analysis is interesting, because it shows that the "resistance factor" is a function of several nondimensional parameters. The most widespread resistance factor equation, probably due to its strong predictive characteristic, is that deduced for flows in circular pipes. For this flows, the resistance factor is expressed as a function of only two nondimensional parameters: the relative roughness and the Reynolds number. When applying the same analysis for stepped channels, the resistance factor is expressed as dependent on more nondimensional parameters, as illustrated by eq. 1 :

$$
\mathrm{f}=\Phi_{1}\left(\operatorname{Re}, \operatorname{Fr}, \alpha, \frac{\mathrm{k}}{\mathrm{L}_{\mathrm{c}}}, \frac{\varepsilon_{\mathrm{p}}}{\mathrm{L}_{\mathrm{c}}}, \frac{\varepsilon_{\mathrm{e}}}{\mathrm{L}_{\mathrm{c}}}, \frac{\varepsilon_{\mathrm{m}}}{\mathrm{L}_{\mathrm{c}}}, \frac{\mathrm{s}}{\mathrm{L}_{\mathrm{c}}}, \frac{1}{\mathrm{~L}_{\mathrm{c}}}, \frac{\mathrm{L}_{\mathrm{c}}}{\mathrm{B}}, \mathrm{C}\right)
$$

$\mathrm{f}$ is the resistance factor. Because the obtained equation is identical to the Darcy-Weisbach equation, the name is preserved. The other variables are: $\operatorname{Re}=$ Reynolds number, $\mathrm{Fr}=$ Froude number, $\alpha=\operatorname{atg}(\mathrm{s} / \mathrm{l}), \mathrm{k}=\mathrm{s} \cos \alpha, \mathrm{L}_{\mathrm{c}}=$ characteristic length, $\varepsilon=$ sand roughness (the subscripts "p", "e "and "m" correspond to the floor of the step, to the vertical step face and the side walls, respectively), $\mathrm{s}=$ step height, $\mathrm{l}=$ step length, $\mathrm{B}=$ width of the channel, $\mathrm{C}=$ void fraction.

Many equations for $\mathrm{f}$ have been proposed for stepped channels since 1990. Due to the practical difficulties in measuring the position of the free surface accurately and to the increasing of the two-phase region, the values of the resistance factor presented in the literature vary in the range of about 0.05 to 5 ! There are different causes for this range, which details are useful to understand it. It is known that, by measuring the depth of the mixture and using this result in the calculation of $\mathrm{f}$, the obtained value is higher than that calculated without the volume of air. This is perhaps one of the main reasons for the highest values. On the other hand, considering the lower values (the range from 0.08 to 0.2 , for example), they may be also affected by the difficulty encountered when measuring depths in multiphase flows. Even the depths of the single-phase region are not easy to measure, because high-frequency oscillations prevent the precise definition of the position of the free surface, or its average value. Let us consider the following analysis, for which the DarcyWeisbach equation was rewritten to represent wide channels

$$
\mathrm{f}=\frac{8 \mathrm{gh}^{3} \mathrm{I}_{\mathrm{f}}}{\mathrm{q}^{2}}
$$

in which: $\mathrm{g}=$ acceleration of the gravity, $\mathrm{h}$ = flow depth, $\mathrm{I}_{\mathrm{f}}=$ slope of the energy line, $\mathrm{q}=$ unit discharge. The derivative of equation (2), with respect to $f$ and $h$, results $\frac{\partial f}{\partial q}=-\frac{16 \mathrm{gh}^{3} \mathrm{I}_{f}}{\mathrm{q}^{3}}$ and $\frac{\partial f}{\partial h}=\frac{24 \mathrm{gh}^{2} \mathrm{I}_{\mathrm{f}}}{\mathrm{q}^{2}}$, respectively, which are used to obtain equation 3 . 
This equation expresses the propagation of the uncertainty of $f$, for which it was assumed that the errors are statistically independent and that the function $f=f(q, h)$ varies smoothly with respect to the error propagation.

$$
\frac{\Delta \mathrm{f}}{\mathrm{f}}=\sqrt{4\left(\frac{\Delta \mathrm{q}}{\mathrm{q}}\right)^{2}+9\left(\frac{\Delta \mathrm{h}}{\mathrm{h}}\right)^{2}}
$$

Assuming $\mathrm{I}_{\mathrm{f}}=1 \pm 0$ (that is, no uncertainty for $\mathrm{I}_{\mathrm{f}}$ ), $\mathrm{h}=0.05 \pm 0.001 \mathrm{~m}$ and $\mathrm{q}=0.25 \pm 0.005 \mathrm{~m}^{2} / \mathrm{s}$, the relative uncertainty of the resistance factor is around $7.2 \%$. The real difficulty in defining the position of the free surface imposes higher relative uncertainties. So, for $\Delta \mathrm{h}=3$ $\mathrm{mm}$, we have $\Delta \mathrm{f} / \mathrm{f}=18.4 \%$ and for $\Delta \mathrm{h}=5 \mathrm{~mm}$, the result is $\Delta \mathrm{f} / \mathrm{f}=30.3 \%$. These $\Delta \mathrm{h}$ values are possible in laboratory measurements.

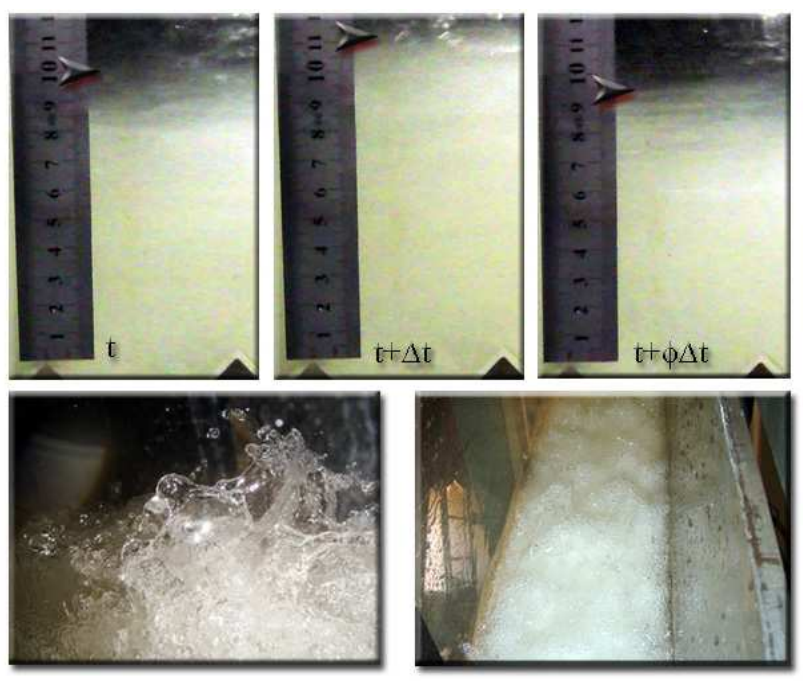

Fig. 4. Behavior of the free surface $(\phi>1)$

Figure 4 contains sequential images of a multiphase flow, obtained by Simões (2011). They illustrate a single oscillation of the mean position of the surface with amplitude close to $15 \mathrm{~mm}$. The first three pictures were taken under ambient lighting conditions, generating images similar to the perception of the human eye. The last two photographs were obtained with a high speed camera, showing that the shape of the surface is highly irregular, with portions of fluid forming a typical macroscopic interface under turbulent motion. It is evident that the method used to measure the depth of such flows may lead to incorrect results if these aspects are not well defined and the measurement equipment is not adequate.

Figure 4 shows that it is difficult to define the position of the free surface. Simões et al. (2011) used an ultrasonic sensor, a high frequency measurement instrument for data acquisition, during a fairly long measurement time, and presented results of the evolution of the two-phase flow that show a clear oscillating pattern, also allowing to observe a transition length between the "full water" and "full mixture" regions of the flows along stepped spillways. Details on similar aspects for smooth spillways were presented by 
Wilhelms \& Gulliver (2005), while reviews of equations and values for the resistance factor were presented by Chanson (2002), Frizell (2006), Simões (2008), and Simões et al. (2010).

\section{Energy dissipation}

The energy dissipated in flows along stepped spillways can be defined as the difference between the energy available near the crest and the energy at the far end of the channel, denoted by $\Delta \mathrm{H}$ throughout this chapter. Selecting a control volume that involves the flow of water between the crest (section 0) and a downstream section (section 1), the energy equation can be written as follows:

$$
\mathrm{z}_{0}+\frac{\mathrm{p}_{0}}{\gamma}+\alpha_{0} \frac{\mathrm{V}_{0}^{2}}{2 \mathrm{~g}}=\mathrm{z}_{1}+\frac{\mathrm{p}_{1}}{\gamma}+\alpha_{1} \frac{\mathrm{V}_{1}^{2}}{2 \mathrm{~g}}+\Delta \mathrm{H}
$$

According to the characteristics of flow and the channel geometry, the flows across these sections can consist of air/water mixtures. Assuming hydrostatic pressure distributions, such that $\mathrm{p}_{0} / \gamma=\mathrm{h}_{0}$ and $\mathrm{p}_{1} / \gamma=\mathrm{h}_{1} \cos \alpha$ (Chow, 1959), the previous equation can be rewritten as:

$$
\begin{aligned}
& \Delta \mathrm{H}=\overbrace{\mathrm{z}_{0}-\mathrm{z}_{1}}^{\mathrm{H}_{\mathrm{dam}}}+\mathrm{h}_{0}+\alpha_{0} \frac{\mathrm{q}^{2}}{2 \mathrm{gh}_{0}^{2}}-\left(\mathrm{h}_{1} \cos \alpha+\alpha_{1} \frac{\mathrm{q}^{2}}{2 \mathrm{gh}_{1}^{2}}\right)= \\
& =\left(\mathrm{H}_{\mathrm{dam}}+\mathrm{h}_{0}+\alpha_{0} \frac{\mathrm{h}_{\mathrm{c}}^{3}}{2 \mathrm{~h}_{0}^{2}}\right)\left[1-\left(\mathrm{h}_{1} \cos \alpha+\alpha_{1} \frac{\mathrm{q}^{2}}{2 \mathrm{gh}_{1}^{2}}\right) /\left(\mathrm{H}_{\mathrm{dam}}+\mathrm{h}_{0}+\alpha_{0} \frac{\mathrm{h}_{\mathrm{c}}^{3}}{2 \mathrm{~h}_{0}^{2}}\right)\right]
\end{aligned}
$$

Denoting $\mathrm{H}_{\mathrm{dam}}+\mathrm{h}_{0}+\alpha_{0} \frac{\mathrm{h}_{\mathrm{c}}^{3}}{2 \mathrm{~h}_{0}^{2}}$ by $\mathrm{H}_{\max }$, the previous equation is replaced by:

$$
\frac{\Delta \mathrm{H}}{\mathrm{H}_{\max }}=1-\left(\frac{\mathrm{h}_{1}}{\mathrm{~h}_{\mathrm{c}}}\right)\left(\frac{\cos \alpha+\alpha_{1} \frac{\mathrm{h}_{\mathrm{c}}^{3}}{2 \mathrm{~h}_{1}^{3}}}{\frac{\mathrm{H}_{\mathrm{dam}}}{\mathrm{h}_{\mathrm{c}}}+\frac{\mathrm{h}_{0}}{\mathrm{~h}_{\mathrm{c}}}+\alpha_{0} \frac{\mathrm{h}_{\mathrm{c}}^{2}}{2 \mathrm{~h}_{0}^{2}}}\right)
$$

Taking into account the width of the channel, and using the Darcy-Weisbach equation for a rectangular channel in conjunction with equation 5, the following result is obtained:

$$
\frac{\Delta \mathrm{H}}{\mathrm{H}_{\max }}=1-\left\{\frac{\left[\frac{8 \mathrm{I}_{\mathrm{f}}}{\left(1+2 \mathrm{~h}_{1} / \mathrm{B}\right) \mathrm{f}}\right]^{-1 / 3} \cos \alpha+\frac{\alpha_{1}}{2}\left[\frac{8 \mathrm{I}_{\mathrm{f}}}{\left(1+2 \mathrm{~h}_{1} / \mathrm{B}\right) \mathrm{f}}\right]^{2 / 3}}{\frac{\mathrm{H}_{\mathrm{dam}}}{\mathrm{h}_{\mathrm{c}}}+\frac{\mathrm{h}_{0}}{\mathrm{~h}_{\mathrm{c}}}+\alpha_{0} \frac{\mathrm{h}_{\mathrm{c}}^{2}}{2 \mathrm{~h}_{0}^{2}}}\right\}
$$

Rajaratnam (1990), Stephenson (1991), Hager (1995), Chanson (1993), Povh (2000), Boes \& Hager (2003a), Ohtsu et al. (2004), among others, presented conceptual and empirical equations to calculate the dissipated energy. In most of the cases, the conceptual models can be obtained as simplified forms of equation 6, which is considered a basic equation for flows in spillways. 


\subsubsection{Two phase flow}

The flows along smooth spillways have some characteristics that coincide with those presented by flows along stepped channels. The initial region of the flow is composed only by water ("full water region" 1 in Figure 5a), with a free surface apparently smooth. The position where the thickness of the boundary layer coincides with the depth of flow defines the starting point of the superficial aeration, or inception point (see Figure 5). In this position the effects of the bed on the flow can be seen at the surface, distorting it intensively. Downstream, a field of void fraction $C\left(x_{i}, t\right)$ is generated, which depth along $x_{1}$ (longitudinal coordinate) increases from the surface to the bottom, as illustrated in Figure 5.

The flow in smooth channels indicates that the region (1) is generally monophasic, the same occurring in stepped spillways. However, channels having short side entrances like those used for drainage systems, typically operate with aerated flows along all their extension, from the beginning of the flow until its end. Downstream of the inception point a twodimensional profile of the mean void fraction $C$ is formed, denoted by $\overline{C^{*}}$. From a given position $\mathrm{x}_{1}$ the so called "equilibrium" is established for the void fraction, which implies that $\overline{C^{*}}=\overline{C^{*}}\left(x_{1}\right)$. Different studies, like those of Straub \& Anderson (1958), Keller et al. (1974), Cain \& Wood (1981) and Wood et al. (1983) showed results consistent with the above descriptions, for flows in smooth spillways. Figure $5 b$ shows the classical sketch for the evolution of two-phase flows, as presented by Keller et al. (1974). Wilhelms \& Gulliver (2005) introduced the concepts of entrained air and entrapped air, which correspond respectively to the air flow really incorporated by the water flow and carried away in the form of bubbles, and to the air surrounded by the twisted shape of the free surface, and not incorporated by the water.
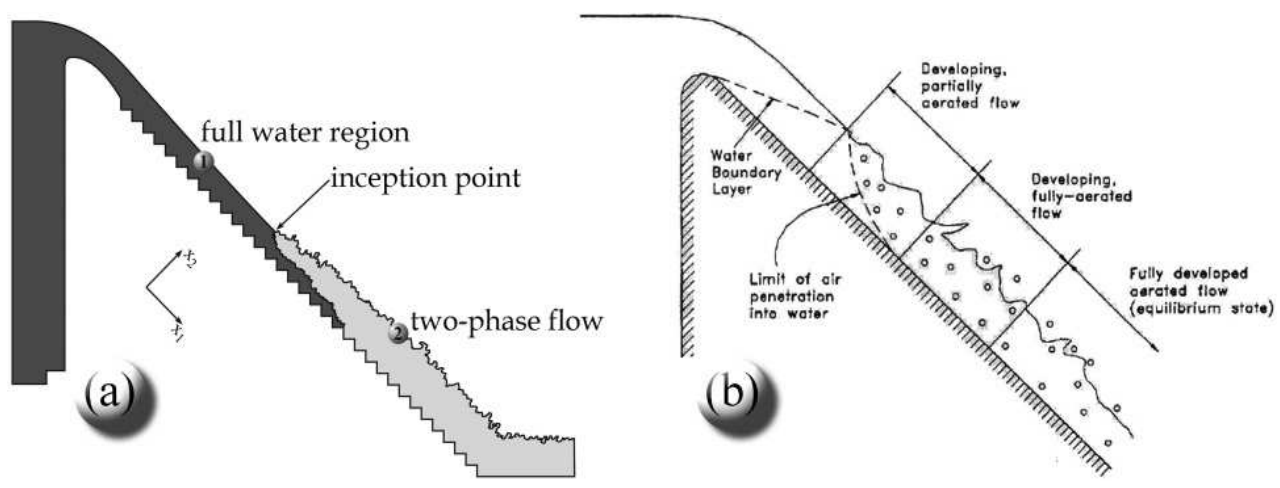

Fig. 5. Skimming flow and possible classifications of the different regions Sources: (a) Simões (2011), (b) Keller et al. (1974)

One of the first studies describing coincident aspects between flows along smooth and stepped channels was presented by Sorensen (1985), containing an illustration indicating the inception point of the aeration and describing the free surface as smooth upstream of this point (Fig. 6a). Peyras et al. (1992) also studied the flow in stepped channels formed by gabions, showing the inception point, as described by Sorensen (1985) (see Figure 6b). 


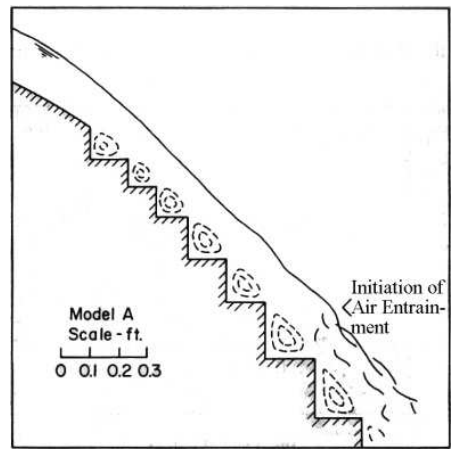

(a)

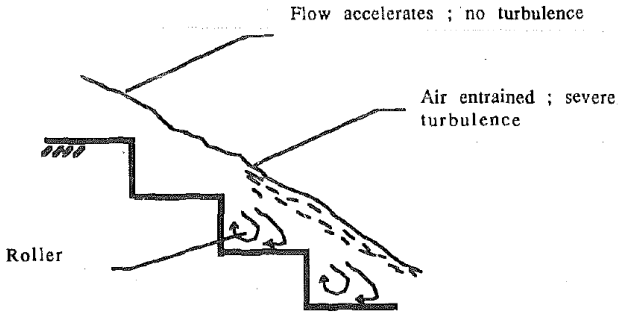

(b)

Fig. 6. Illustration of the flow

Reference: (a) Sorensen (1985, p.1467) and (b) Peyras et al. (1992, p.712).

The sketch of Figure $6 \mathrm{~b}$ emphasizes the existence of rolls downstream from the inception position of the aeration. Further experimental studies, such as Chamani \& Rajaratnam (1999a, p.363) and Ohtsu et al. (2001, p.522), showed that the incorporated air flow distributes along the depth of the flow and reaches the cavity below the pseudo-bottom, where large eddies are maintained by the main flow.

The mentioned studies of multiphase flows in spillways (among others) thus generated predictions for: (1) the position of the inception point of aeration, (2) profiles of void fractions (3) averages void fractions over the spillways, (4) characteristics of the bubbles. As mentioned, frequently the conclusions obtained for smooth spillways were used as basis for studies in stepped spillways. See, for example, Bauer (1954), Straub \& Anderson (1958), Keller \& Rastogi (1977), Cain \& Wood (1981), Wood (1984), Tozzi (1992), Chanson (1996), Boes (2000), Chanson (2002), Boes \& Hager (2003b) and Wilhelms \& Gulliver (2005).

\subsubsection{Other topics}

In addition to the general aspects mentioned above, a list of specific items is also presented here. The first item, cavitation, is among them, being one of major relevance for spillway flows. It is known that the air/water mixture does not damage the spillway for void fractions of about $5 \%$ to $8 \%$ (Peterka, 1953). For this reason, many studies were performed aiming to know the void fraction near the solid boundary and to optimize the absorption of air by the water. Additionally, the risk of cavitation was analyzed based on instant pressures observed in physical models. Some specific topics are show below:

1. Cavitation;

2. Channels with large steps;

3. Stepped chutes with gabions;

4. Characteristics of hydraulic jumps downstream of stepped spillways;

5. Plunging flow;

6. Recommendations for the design of the height of the side walls;

7. Geometry of the crest with varying heights of steps;

8. Aerators for stepped spillways;

9. Baffle at the far end of the stepped chute; 
10. Use of spaced steps;

11. Inclined step and end sills;

12. Side walls converging;

13. Use of precast steps;

14. Length of stilling basins.

As can be seen, stepped chutes are a matter of intense studies, related to the complex phenomena that take place in the flows along such structures.

\section{Experimental study}

\subsection{General information}

The experimental results presented in this chapter were obtained in the Laboratory of Environmental Hydraulics of the School of Engineering at São Carlos (University of Sao Paulo). The experiments were performed in a channel with the following characteristics: (1) Width: B $=0.20 \mathrm{~m}$, (2) Length $=5.0 \mathrm{~m}, 3.5 \mathrm{~m}$ was used, (3) Angle between the pseudo bottom and the horizontal: $\alpha=45$; (4) Dimensions of the steps $\mathrm{s}=1=0.05 \mathrm{~m}$ ( $\mathrm{s}=$ step height $\mathrm{l}=$ length of the floor), and (5) Pressurized intake, controlled by a sluice gate. The water supply was accomplished using a motor/pump unit (Fig. 7) that allowed a maximum flow rate of $300 \mathrm{~L} / \mathrm{s}$. The flow rate measurements were performed using a thin-wall rectangular weir located in the outlet channel, and an electromagnetic flow meter positioned in the inlet tubes (Fig. 7b), used for confirmation of the values of the water discharge.

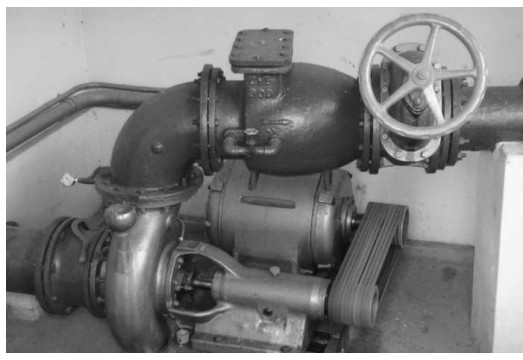

(a)

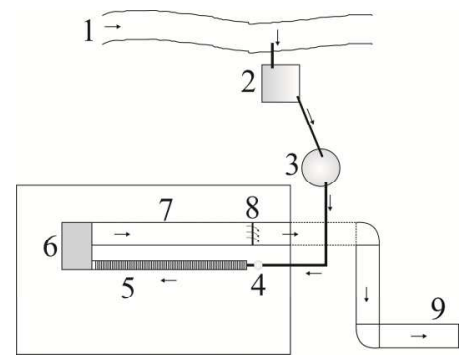

(b)

Fig. 7. a) Motor/pump system.; b) Schematic drawing of the hydraulic circuit: (1) river, (2) engine room, (3) reservoir, (4) electromagnetic flowmeter, (5) stepped chute, (6) energy sink, (7) outlet channel; (8) weir, (9) final outlet channel.

The position of the free surface was measured using acoustic sensors (ultrasonic sensors), as previously done by Lueker et al. (2008). They were used to measure the position of the free surface of the flows tested in a physical model of the auxiliary spillway of the Folsom Dam, performed at the St. Anthony Falls Laboratory, University of Minnesota. A second study that employed acoustic probes was Murzyn \& Chanson (2009), however, for measuring the position of the free surface in hydraulic jumps.

In the present study, the acoustic sensor was fixed on a support attached to a vehicle capable of traveling along the channel, as shown in the sketch of Figure 8. For most experiments, along the initial single phase stretch, the measurements were taken at sections distant $5 \mathrm{~cm}$ from each other. After the first $60 \mathrm{~cm}$, the measurement sections were spaced $10 \mathrm{~cm}$ from 
each other. The sensor was adjusted to obtain 6000 samples (or points) using a frequency of $50 \mathrm{~Hz}$ at each longitudinal position. These 6000 points were used to perform the statistical calculations necessary to locate the surface and the drops that formed above the surface. A second acoustic sensor was used to measure the position of the free surface upstream of the thin wall weir, in order to calculate the average hydraulic load and the flow rates used in the experiments. The measured flow rates, and other experimental parameters of the different runs, are shown in Table 1.

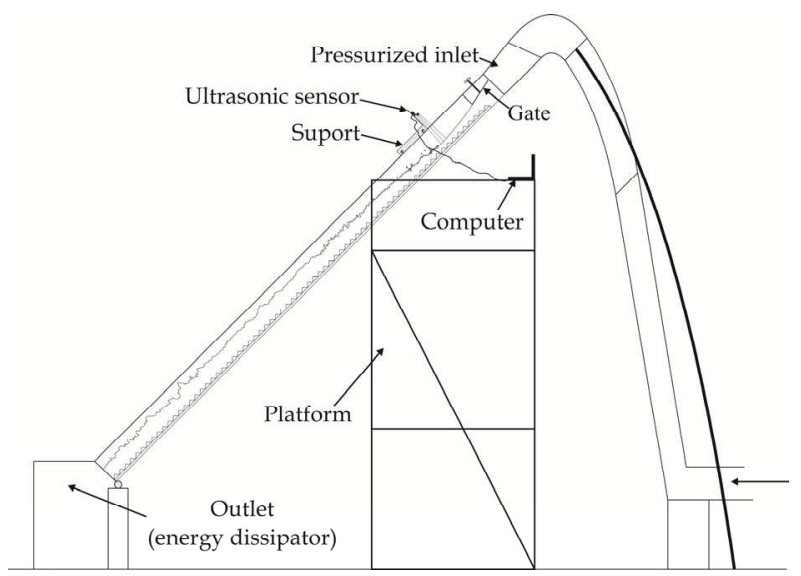

Fig. 8. Schematic of the arrangement used in the experiments

\begin{tabular}{cccccccc}
\hline No & Experiment name & $\begin{array}{c}\mathrm{Q} \\
{\left[\mathrm{m}^{3} / \mathrm{s}\right]}\end{array}$ & Profile & $\begin{array}{c}\mathrm{q} \\
{\left[\mathrm{m}^{2} / \mathrm{s}\right]}\end{array}$ & $\begin{array}{c}\mathrm{h}_{\mathrm{c}} \\
{[\mathrm{m}]}\end{array}$ & $\begin{array}{c}\mathrm{s} / \mathrm{h}_{\mathrm{c}} \\
{[-]}\end{array}$ & $\begin{array}{c}\mathrm{h}(0) \\
{[\mathrm{m}]}\end{array}$ \\
\hline 1 & Exp. 2 & 0.0505 & $\mathrm{~S}_{2}$ & 0.252 & 0.187 & 0.268 & 0.103 \\
2 & Exp. 3 & 0.0458 & $\mathrm{~S}_{2}$ & 0.229 & 0.175 & 0.286 & 0.101 \\
3 & Exp. 4 & 0.0725 & $\mathrm{~S}_{2}$ & 0.362 & 0.238 & 0.211 & 0.106 \\
4 & Exp. 5 & 0.0477 & $\mathrm{~S}_{2}$ & 0.239 & 0.180 & 0.278 & 0.087 \\
5 & Exp. 6 & 0.0833 & $\mathrm{~S}_{3}$ & 0.416 & 0.261 & 0.192 & 0.092 \\
6 & Exp. 7 & 0.0504 & $\mathrm{~S}_{2}$ & 0.252 & 0.187 & 0.268 & 0.089 \\
7 & Exp. 8 & 0.0073 & $\mathrm{~S}_{2}$ & 0.0366 & 0.051 & 0.971 & 0.027 \\
8 & Exp. 9 & 0.0074 & $\mathrm{~S}_{2}$ & 0.0368 & 0.052 & 0.967 & 0.024 \\
9 & Exp. 10 & 0.0319 & $\mathrm{~S}_{2}$ & 0.159 & 0.137 & 0.364 & 0.058 \\
10 & Exp. 11 & 0.0501 & $\mathrm{~S}_{3}$ & 0.250 & 0.186 & 0.269 & 0.06 \\
11 & Exp. 14 & 0.0608 & $\mathrm{~S}_{2}$ & 0.304 & 0.211 & 0.237 & 0.089 \\
12 & Exp. 15 & 0.0561 & $\mathrm{~S}_{2}$ & 0.280 & 0.200 & 0.250 & 0.087 \\
13 & Exp. 16 & 0.0265 & $\mathrm{~S}_{2}$ & 0.133 & 0.122 & 0.411 & 0.046 \\
14 & Exp. 17 & 0.0487 & $\mathrm{~S}_{2}$ & 0.244 & 0.182 & 0.274 & 0.072 \\
15 & Exp. 18 & 0.0431 & $\mathrm{~S}_{2}$ & 0.216 & 0.168 & 0.298 & 0.074 \\
16 & Exp. 19 & 0.0274 & $\mathrm{~S}_{2}$ & 0.137 & 0.124 & 0.402 & 0.041 \\
17 & Exp. 20 & 0.0360 & $\mathrm{~S}_{2}$ & 0.180 & 0.149 & 0.336 & 0.068 \\
18 & Exp. 21 & 0.0397 & $\mathrm{~S}_{2}$ & 0.198 & 0.159 & 0.315 & 0.071 \\
\hline
\end{tabular}

Table 1. General data related to experiments 
As can be seen in Figure 4, the positioning of the free surface is complex due to its highly irregular structure, especially downstream from the inception point. One of the characteristics of measurements conduced with acoustic sensors is the detection of droplets ejected from the surface. These values are important for the evaluation of the highest position of the droplets and sprays, but have little influence to establish the mean profiles of the free surface. This is shown in Figure 9a, which contains the relative errors calculated considering the mean position obtained without the outliers (droplets). The corrections were made using standard criteria used for box plots. The maximum percentage of rejected samples (droplets) was 8.3\% for experiment No 5 .

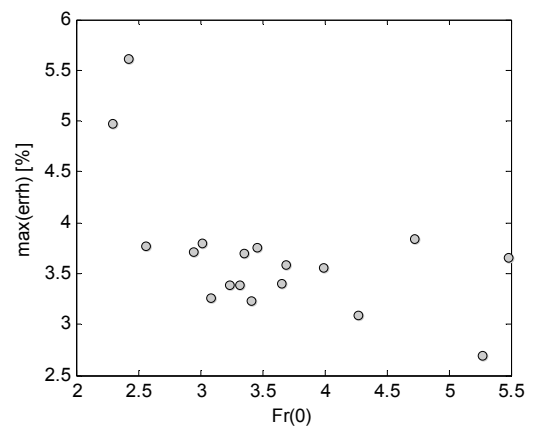

(a)

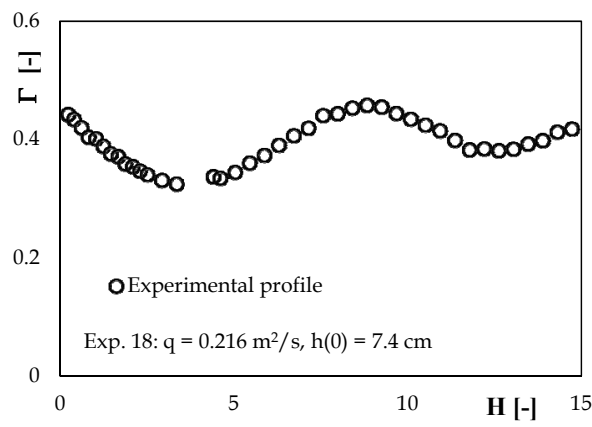

(b)

Fig. 9. (a) Maximum relative deviations corresponding to the eighteen experiments, in which: errh $=100|| h^{(1)}-h^{(2)}|| / h^{(2)}, h^{(i)}=$ mean value obtained with the acoustic sensor, $\mathrm{i}=$ 1 (original sample), $\mathrm{i}=2$ (sample without outliers) and $\operatorname{Fr}(0)=$ Froude number at $x=0$; $(b)$ Mean experimental profile due to Exp.18. The deviations were used to obtain the maximum position of the droplets, but were ignored when obtaining the mean profile of the surface.

Figure $9 \mathrm{~b}$ presents an example of a measured average profile obtained in this study. As can be seen, an $S_{2}$ profile is formed in the one-phase region. The inception point of the aeration is given by the position of the first minimum in the measured curve. It establishes the end of the $S_{2}$ curve and the beginning of the "transition length", as defined by Simões et al. (2011). As shown by the mentioned authors, the surface of the mixture presents a wavy shape, also used to define the end of the transition length, given by the first maximum of the surface profile.

\subsection{Results}

\subsubsection{Starting position of the aeration (inception point)}

As mentioned, the starting position of the aeration was set based on the minimum point that characterizes the far end of the $S_{2}$ profile. In some experiments, this minimum showed a certain degree of dispersion, so that the most probable position was chosen. To quantify the position of the inception point of the aeration, the variables involved in a first instance were $\mathrm{L}_{\mathrm{A}} / \mathrm{k}$ and $\mathrm{F}_{\mathrm{r}}{ }^{*}$, adjusting a power law between them, as already used by several authors. (e.g., Chanson, 2002; Sanagiotto, 2003) Equation 7 shows the best adjustment obtained for the present set of data, with a correlation coefficient of 0.91 . Considering the four variables $\mathrm{L}_{\mathrm{A}} / \mathrm{k}, \mathrm{h}(0) / \mathrm{k}, \operatorname{Re}(0)$, and $\mathrm{F}_{\mathrm{r}}{ }^{*}$ (see figure $6 \mathrm{a}$ for the definitions of the variables), a second 
equation is presented, as a sum of the powers of the variables. Equation 8 presents a correlation coefficient of 0.98 , leading to a good superposition between data and adjusted curve, as can be seen in Fig.10b.

$$
\begin{gathered}
\frac{\mathrm{L}_{\mathrm{A}}}{\mathrm{k}}=1.61 \mathrm{~F}_{\mathrm{r}}^{* 1.06} \\
\frac{\mathrm{L}_{\mathrm{A}}}{\mathrm{k}}=699.97 \mathrm{~F}_{\mathrm{r}}^{*-6,33}+34.22\left[\frac{\mathrm{h}(0)}{\mathrm{k}}\right]^{0.592}-49.45 \operatorname{Re}(0)^{-0.0379}
\end{gathered}
$$

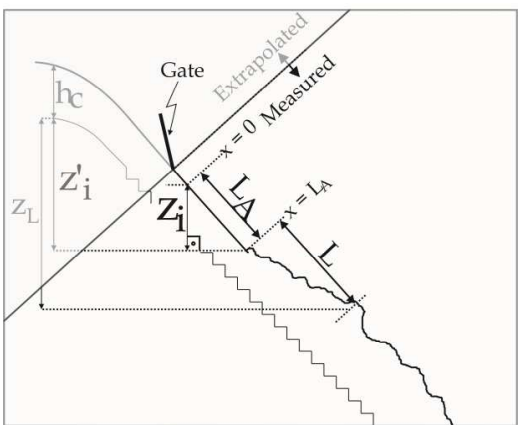

(a)

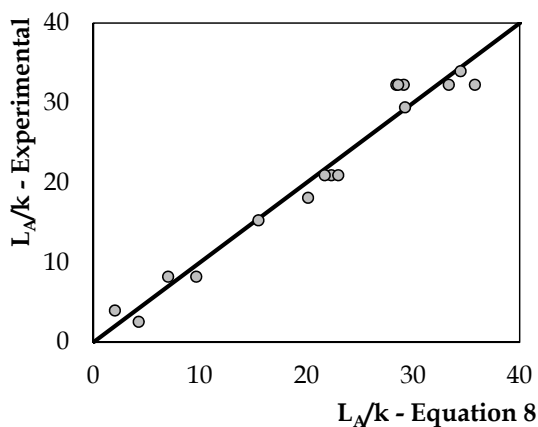

(b)

Fig. 10. Definition of variables related to the start of aeration (a) and comparison between measured data and calculated values using the adjusted equation 8 .

Equations 7 and 8 show very distinct behaviors for the involved parameters. For example, the dependence of $\mathrm{L}_{\mathrm{A}} / \mathrm{k}$ on $\mathrm{F}_{\mathrm{r}}{ }^{*}$ shows increasing lengths for increasing $\mathrm{F}_{\mathrm{r}}{ }^{*}$ when using equation 7 , and decreasing lengths for increasing $\mathrm{F}_{\mathrm{r}}{ }^{*}$ when using equation 8 . Additionally, the influence of $h(0) / k$ appears as relevant, when considering the exponent 0.592 . This parameter was used to verify the relevance of $\mathrm{F}_{\mathrm{r}}{ }^{*}$ to quantify the inception point. Although the result points to a possible relevance of the geometry of the flow $(h(0))$, the adequate definition of this parameter for general flows is an open question. It is the depth of the flow at a fixed small distance from the sluice gate in this study, thus directly related to the geometry, but which correspondent to general flows, as already emphasized, must still be defined. In the present analysis, following restrictions apply: $2.09 \leq \mathrm{F}_{\mathrm{r}}{ }^{*} \leq 20.70,0.69 \leq \mathrm{h}(0) / \mathrm{k}$ $\leq 2.99$ and $1.15 \times 10^{5} \leq \operatorname{Re}(0) \leq 7.04 \times 10^{5}$.

Equation 7 can be rewritten using $z_{i} / s$ and $F$, in which $z_{i}=L_{A} \sin \alpha$, and $F$ is the Froude number defined by Boes \& Hager $(2003 \mathrm{~b})$ as $\mathrm{F}=\mathrm{q} / \sqrt{\mathrm{gs}^{3} \sin \alpha}$. In this case $\mathrm{F}_{\mathrm{r}}{ }^{*}=$ $\mathrm{F} /\left(\cos ^{3} \alpha\right)^{1 / 2}$. The correlation coefficient is the same obtained for equation 7 , and the resulting equation, valid for the same conditions of the previous adjustments, is:

$$
\frac{\mathrm{z}_{\mathrm{i}}}{\mathrm{s}}=1.397 \mathrm{~F}^{1.06}
$$

The power laws proposed by Boes (2000) and Boes \& Hager (2003b) were similar to equation 9, but having different coefficients. In order to compare the different proposals, equation 9 
was modified by replacing $z_{i}$ by $z_{i}^{\prime}$ (see Figure 10a). The energy equation was also used, for the region between the critical section (Section 1, represented by the subscript "c") and the initial section of the experiments (Section 2, at $x=0$, represented by (0)). The DarcyWeisbach equation was applied with average values for the hydraulic radius and the velocity. The resulting equation is similar to that proposed by Boes (2000, p.126), who also used the Coriolis coefficient, assumed unity in the present study. Equation (10) is the equation adopted in the present study:

$$
z_{c}-z(0)=\frac{h(0) \cos \alpha+h_{c}^{3} /\left[2 h(0)^{2}\right]-(3 / 2) h_{c}}{1-f \frac{h_{c}^{3}\left(h(0)+h_{c}\right)}{\left(h_{c} h(0)\right)^{2} 16 \sin \alpha} \frac{\left(B+h_{c}+h(0)\right)}{B}}
$$

The calculation of $\mathrm{z}_{\mathrm{i}}^{\prime}$ requires the resistance factor, obtained here applying the methodology described by Simões et al. (2010). The obtained equation presented a correlation coefficient of 0.98 when compared to the measured data, having the form:

$$
z_{i}^{\prime} / s=3.19 F^{0.837}
$$

where: $z_{i}^{\prime}=z_{i}+z_{c}-z(0)$. This equation is valid for the same ranges of the variables shown for equations 7 and 8 . Equation 11 furnishes lower values of $z_{i} / s$ when compared to the equations of Boes (2000, p.126) and Boes \& Hager (2003b). Two reasons for the difference are mentioned here: (1) The method used to calculate the resistance factor, and (2) the definition of the position of the inception point. The mentioned authors defined the starting position of the aeration as the point where the void fraction at the pseudo-bottom is $1 \%$, while the present definition corresponds to the final section of the $S_{2}$ profile. Using the equation of Boes \& Hager (2003b), $\mathrm{z}_{\mathrm{i}}^{\prime} / \mathrm{s}=5.9 \mathrm{~F}^{0.8}$, it is possible to relate these two positions, as shown by equation 12. The position of the void fraction of $1 \%$ at the pseudo-bottom occurs approximately at 1.85 times the position of the final section of the $S_{2}$ profile, with both lengths having their origin at the crest of the spillway.

$$
\frac{\left.\mathrm{z}_{\mathrm{i}}^{\prime}\right)_{1 \%}}{\left.\mathrm{z}_{\mathrm{i}}^{\prime}\right)_{S_{2}}}=\frac{1.85}{\mathrm{~F}^{0.037}}
$$

In equation $\left.12, z_{i}^{\prime}\right)_{1 \%}$ corresponds to the length defined by the equation of Boes \& Hager $(2003 b)$, and $\left.z_{i}^{\prime}\right)_{s 2}$ corresponds to the length defined by eq. 11 . Transforming equation 11 considering the variables $\mathrm{L}_{\mathrm{A}^{*}} / \mathrm{k}$ and $\mathrm{F}_{\mathrm{r}}{ }^{*}$, in which $\mathrm{L}_{\mathrm{A}^{*}}$ correspond to $\mathrm{Z}_{\mathrm{i}}^{\prime}$, the following relation between the Froude numbers is obtained

$$
\mathrm{F}=\eta \mathrm{F}_{\mathrm{r}}^{*} \Rightarrow \frac{\mathrm{q}}{\sqrt{\mathrm{gs}^{3} \sin \alpha}}=\eta \frac{\mathrm{q}}{\sqrt{\mathrm{gk}^{3} \sin \alpha}} \Rightarrow \eta=\left(\frac{\mathrm{k}}{\mathrm{s}}\right)^{3 / 2} \Rightarrow \mathrm{F}=\left(\frac{\mathrm{k}}{\mathrm{s}}\right)^{3 / 2} \mathrm{~F}_{\mathrm{r}}^{*}
$$

and remembering that $\mathrm{L}_{\mathrm{A}^{*}} / \mathrm{k}=\left(\mathrm{z}_{\mathrm{i}}^{\prime} / \mathrm{s}\right) /(\sin \alpha \cos \alpha)$, leads then to:

$$
\frac{\mathrm{L}_{\mathrm{A}^{*}}}{\mathrm{k}}=4.13 \mathrm{~F}_{\mathrm{r}}^{*} 0.837
$$

The behavior of equation 13 in comparison with experimental data is illustrated in Figure 11 , which contains experimental data found in the literature, as well as two additional 
predictive curves. Observe that, except for the first two points (obtained in the present study), the results are located close to the curve defined by Matos (1999). It is also interesting to note that the equations proposed by Matos (1999) and Sanagiotto (2003) are approximately parallel.

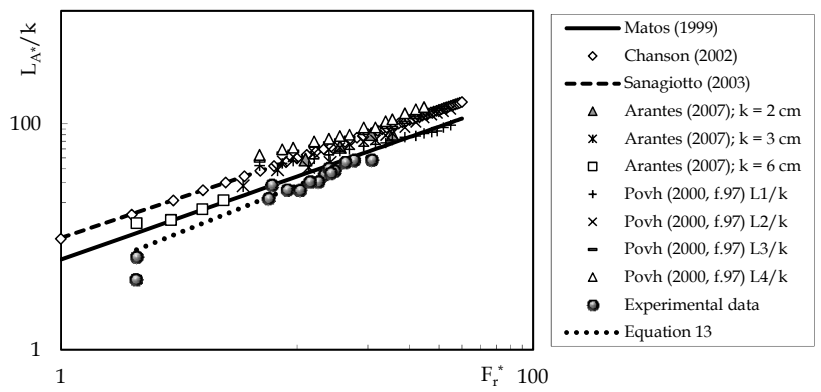

Fig. 11. Starting position of the aeration: a comparison between the experimental data of this research, the equation obtained in this work and data (experimental and numerical) of different authors.

\subsubsection{Depths at the end of $S_{2}$}

As in the previous case, power laws and sum of power laws were used to quantify the flow depth at the inception point, that is, in the final section of the $S_{2}$ profile. Equations 14 and 15 were then obtained, with correlation coefficients 0.97 and 0.98 , respectively. Figure 12 contains a comparison with data from different sources.

$$
\begin{gathered}
\frac{\mathrm{h}_{\mathrm{A}}}{\mathrm{k}}=0.363 \mathrm{~F}_{\mathrm{r}}^{* 0.609} \\
\frac{\mathrm{h}_{\mathrm{A}}}{\mathrm{k}}=0.791 \mathrm{~F}_{\mathrm{r}}^{*-6.98}+1.285\left[\frac{\mathrm{h}(0)}{\mathrm{k}}\right]^{0.567}-19.56 \operatorname{Re}(0)^{-0.322}
\end{gathered}
$$

Equations 14 and 15 are restricted to: $2.09 \leq \mathrm{F}_{\mathrm{r}}{ }^{*} \leq 20.70,0.69 \leq \mathrm{h}(0) / \mathrm{k} \leq 2.99$ and $1.15 \times 10^{5} \leq$ $\operatorname{Re}(0) \leq 7.04 \times 10^{5}$.

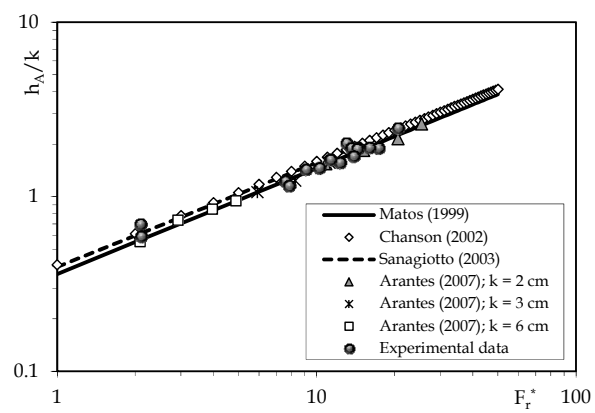

Fig. 12. Depth in the starting position of the aeration based on the final section of the $S_{2}$ profile: comparison with experimental and numerical data of different sources. 


\subsubsection{Transition to two-phase flow}

The experiments showed that the averaged values of the depths form a free surface profile composed by a decreasing region $\left(\mathrm{S}_{2}\right)$ followed by a growing region that extends up to a maximum depth, from which a wavy shape is formed downstream, as illustrated by Figure 13a. The maximum value which limits the growing region is denoted by $h_{2}$. The length of the transition between the minimum $\left(\mathrm{h}_{\mathrm{A}}\right)$ and the maximum $\left(\mathrm{h}_{2}\right)$ is named here "transition length", and is represented by $\mathrm{L}$, a distance parallel to the pseudo bottom, as shown in Figure $13 a . h_{A} / k$ was related to $h_{2} / k$ using a power law (equation 16), showing a good superposition between experimental data and the adjusted equation, as shown in figure $13 \mathrm{~b}$, with a correlation coefficient of 0.99 .

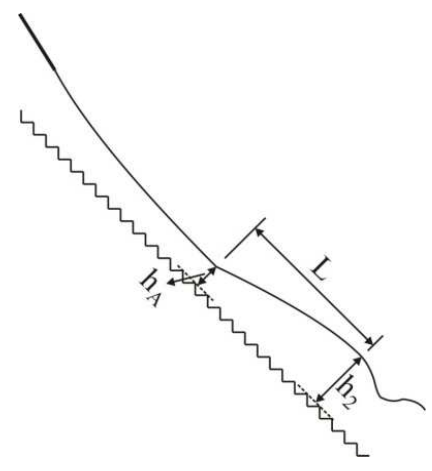

(a)

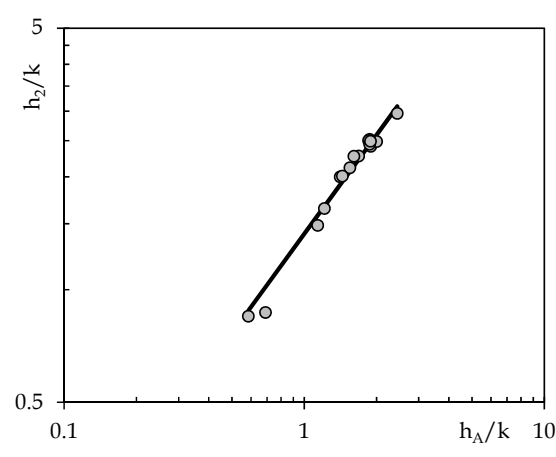

(b)

Fig. 13. a) Definition of the depth $h_{2}$ and the transition length $L$, and b) correlation between the depth at the start of aeration $\left(\mathrm{h}_{\mathrm{A}} / \mathrm{k}\right)$ and the depth corresponding to the first wave crest $\left(h_{2} / k\right)$, expressed by equation 16 .

$$
\frac{\mathrm{h}_{2}}{\mathrm{k}}=1.408\left(\frac{\mathrm{h}_{\mathrm{A}}}{\mathrm{k}}\right)^{0.879}
$$

As in previous cases, also the parameters $\mathrm{F}_{\mathrm{r}}{ }^{*}, \mathrm{~h}(0) / \mathrm{k}$ and $\operatorname{Re}(0)$ were used to quantify $\mathrm{h}_{2} / \mathrm{k}$, for which equation 17 was obtained, with a correlation coefficient of 0.99 . The ranges of validity of equations 16 and 17 are the same as for equations 7 and 8 .

$$
\frac{\mathrm{h}_{2}}{\mathrm{k}}=0.319 \mathrm{~F}_{\mathrm{r}}^{* 0.553}+0.529\left[\frac{\mathrm{h}(0)}{\mathrm{k}}\right]^{0.744}-1.6 \times 10^{4} \operatorname{Re}(0)^{-2.1 \times 10^{5}}
$$

The transition length between the last "full water" section (the last $S_{2}$ section) and the first "full mixture" section, or, in other words, the section at which the air reaches the pseudobottom, could be well characterized using the ultrasound sensor. From a practical point of view, this length is relevant because it involves a region of the spillway still unprotected, due to the absence of air near the bottom. Experimental verification of void fractions is still necessary to establish the void percentage attained at the pseudo-bottom in the mentioned section. An analysis is presented here considering the hypothesis that the "full mixture" section defined by the maximum of the measured depths corresponds to the $1 \%$ void fraction defined by Boes (2000) and Boes \& Hager (2003b). 
Combining the transition lengths with the values of $\mathrm{L}_{\mathrm{A}^{*}}\left(\right.$ or $\left.\mathrm{z}_{\mathrm{i}}^{\prime}\right)$, the positions of the inception point considering this new origin are then obtained. This length was correlated with the dimensionless parameters $\left(\mathrm{z}_{\mathrm{i}}^{\prime}+\mathrm{L} \sin \alpha\right) / \mathrm{s}=\mathrm{z}_{\mathrm{L}} / \mathrm{s}$ and $\mathrm{F}=\mathrm{q} /\left(\mathrm{gs}^{3} \sin \alpha\right)^{0,5}$. Equation 18 was then obtained, with a correlation coefficient of 0.95 . Figure 14 illustrates the behavior of this adjustment in relation to the experimental data. The same figure also shows the curve obtained with the equation of Boes \& Hager (2003b), showing that the two forms of analyses generate very similar results.

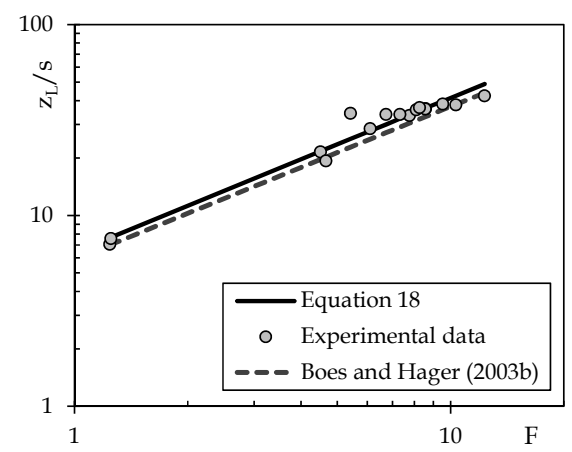

Fig. 14. Starting position of the aeration considering the present analysis (equation 18), corresponding to the position of the maximum of the measured depths, and the equation of Boes \& Hager (2003b), $\mathrm{z}_{\mathrm{i}}^{\prime} / \mathrm{s}=5.9 \mathrm{~F}^{0.8}$ (in this case, $\mathrm{z}_{\mathrm{i}}^{\prime}$ corresponds to a mean void fraction of $1 \%$ at the pseudo bottom).

$$
\frac{\mathrm{z}_{\mathrm{L}}}{\mathrm{s}}=6.4 \mathrm{~F}^{0.81}
$$

The equations proposed for Boes (2000) and Boes \& Hager (2003b) allow to relate $\mathrm{z}_{\mathrm{L}} / \mathrm{s}$ with the position of the $1 \%$ void fraction on the pseudo bottom, leading to:

$$
\begin{gathered}
\left.\frac{\left.\mathrm{z}_{\mathrm{i}}^{\prime}\right)_{1 \%}}{\mathrm{z}_{\mathrm{L}}}=0.73 \mathrm{~F}^{0.03} \quad \mathrm{z}_{\mathrm{i}}^{\prime}\right)_{1 \%} \text { from Boes }(2000) \\
\left.\frac{\left.\mathrm{z}_{\mathrm{i}}^{\prime}\right)_{1 \%}}{\mathrm{z}_{\mathrm{L}}}=\frac{0.92}{\mathrm{~F}^{0.01}} \quad \mathrm{z}_{\mathrm{i}}^{\prime}\right)_{1 \%} \text { from Boes \& Hager }(2003 \mathrm{~b})
\end{gathered}
$$

As can be seen, the results show different trends in relation to the Froude number. Such differences may be related to the values of the adjusted exponents, which are close, but not the same. Equation 18 is very similar to equation 11, with the Froude number in both equations having similar exponents, and the coefficient of equation 18 being 2 times bigger that the coefficient of equation 11. This result is close to the factor of 1.85 obtained with equation 12. Figure 15 shows that the results obtained with the present analysis are close to those obtained with the equation Boes \& Hager (2003b), suggesting to use the maximum depth to locate the beginning of the bottom aeration, or, in other words, the position where there is a void fraction of $1 \%$ at the bottom. It is important to emphasize that the measurement of the position of the free surface is much simpler than the measurement of 
the concentrations at the pseudo-bottom, so that we suggest the present methodology to evaluate the position of the beginning of the "full mixed" region. Of course, the void fraction measurements at the bottom were important to allow the present comparison.

Of course, having a first confirmation, it is possible to obtain the same information involving the different axes used in spillway studies. For example, it is possible to $\mathrm{L}_{\mathrm{A}}{ }^{*} / \mathrm{k}$ with $\mathrm{F}_{\mathrm{r}}{ }^{*}, \mathrm{LA}_{\mathrm{A}}{ }^{*}$ being the sum of $\mathrm{L}_{\mathrm{A}^{*}}$ with $\mathrm{L}$. The result is equation 21 , with a correlation coefficient of 0.95 , and which behavior is illustrated in Figure 11, where it is compared with data from other sources. In general, there is a good agreement of equation 21 with most of the results of the cited studies. Special mention made be made for the data L4/k obtained by Povh (2000) (the L4 position corresponds to the fully-aerated section of the flow), the data of Chanson (2002), and Sanagiotto (2003).

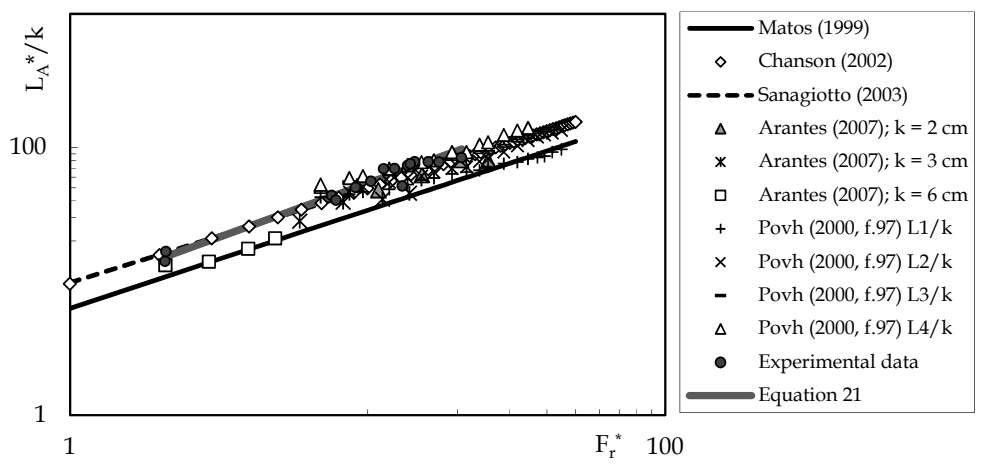

Fig. 15. Inception point considering different equations of the literature and equation 21: a comparison with data from different authors

$$
\frac{\mathrm{L}_{\mathrm{A}}^{*}}{\mathrm{k}}=8.4 \mathrm{~F}^{0.81}
$$

Following the previous procedures followed in this section, equation 22 was also obtained, involving the geometrical information of the flow and the Reynolds number, presenting a correlation coefficient of 0.98 .

$$
\frac{\mathrm{L}_{\mathrm{A}}^{*}}{\mathrm{k}}=2397.09 \mathrm{~F}_{\mathrm{r}}^{*}-6.36-32.49\left[\frac{\mathrm{h}(0)}{\mathrm{k}}\right]^{-1.29}+0.212 \operatorname{Re}(0)^{0.452}
$$

The restrictions of this study are $2.09 \leq \mathrm{F}_{\mathrm{r}}{ }^{*} \leq 20.70,0.69 \leq \mathrm{h}(0) / \mathrm{k} \leq 2.99$ and $1.15 \times 10^{5} \leq \operatorname{Re}(0) \leq$ $7.04 \times 10^{5}$.

\subsubsection{Turbulence intensity and kinetic energy}

The time derivatives of the position of the free surface were used to evaluate the turbulent intensity $\left(\mathrm{w}^{\prime}\right)$ and, assuming isotropy (as a first approximation), the turbulent kinetic energy $\left(\mathrm{k}_{\mathrm{e}}\right)$, defined in equations (23) and (24):

$$
\mathrm{w}^{\prime}=\sqrt{\overline{\mathrm{w}^{2}}}
$$




$$
\mathrm{k}_{\mathrm{e}}=\frac{3}{2} \mathrm{w}^{12}
$$

Also a relative intensity and a dimensionless turbulent kinetic energy were defined, written in terms of the critical kinetic energy (all parameters per unit mass of fluid), which are represented by equations (25) and (26):

$$
\begin{gathered}
\mathrm{ir}=\frac{\mathrm{w}^{\prime}}{\mathrm{V}_{\mathrm{c}}} \\
\mathrm{k}_{\mathrm{e}}{ }^{*}=\mathrm{ir}^{2}
\end{gathered}
$$

$\mathrm{V}_{\mathrm{c}}$ is given by $\mathrm{V}_{\mathrm{c}}=\left(\mathrm{gh}_{\mathrm{c}}\right)^{1 / 2}$; and $\mathrm{h}_{\mathrm{c}}=\left(\mathrm{q}^{2} / \mathrm{g}\right)^{1 / 3}$ (critical depth).

Figure 16 contains the results obtained in the present study for the relative intensities and dimensionless kinetic energy, both plotted as a function of the dimensionless position $\mathrm{z} / \mathrm{z}_{\mathrm{i}}$, where $\mathrm{z}=$ vertical axis with origin at $\mathrm{x}=0$ and positive downwards. Four different regions may be defined for the obtained graphs: (1) Single-phase growing region, (2) Single-phase

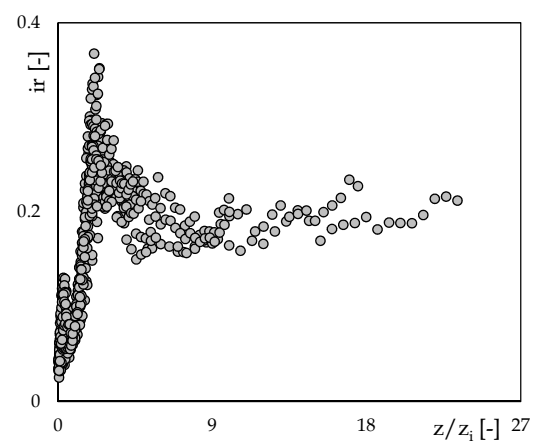

(a)

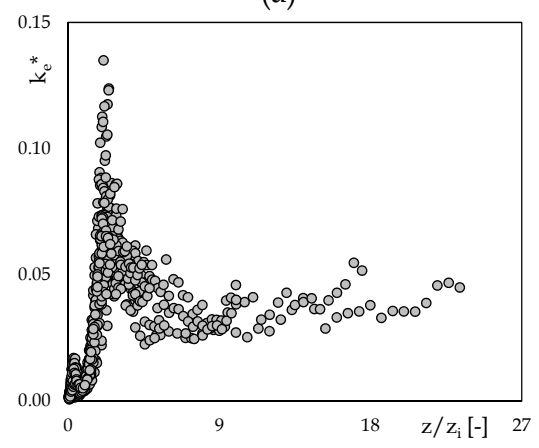

(c)

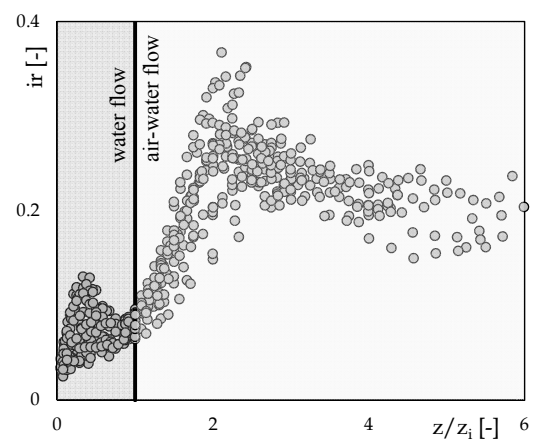

(b)

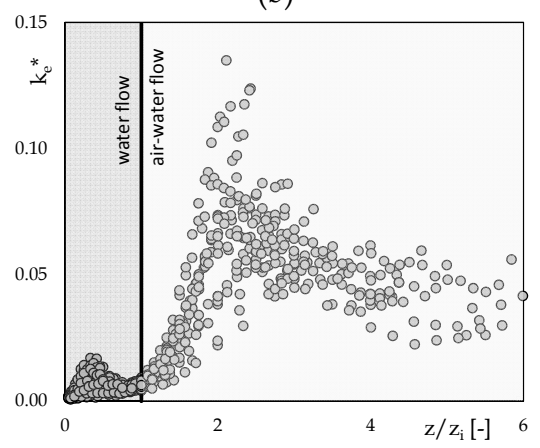

(d)

Fig. 16. Relative turbulent intensity and turbulent kinetic energy plotted against the dimensionless vertical position. The starting position of the aeration is defined as the final section of the $S_{2}$ profile. $(a, b)$ turbulent intensity; $(b, c)$ dimensionless kinetic energy. 
decay region, which is limited downwards around the point $z / z_{i}=0.9$, (3) Two-phase growing region, limited by $\sim 0.9<\mathrm{z} / \mathrm{z}_{\mathrm{i}}<\sim 2.11$, and (4) Two-phase decay region.

Considering the decay region limited by $2.5<\mathrm{z} / \mathrm{z}_{\mathrm{i}}<14$, a power law of the type $\mathrm{k}_{\mathrm{e}}=\mathrm{a}\left(\mathrm{z} / \mathrm{z}_{\mathrm{i}}\right)^{-\mathrm{n}}$ was adjusted, obtaining $\mathrm{n}=0.46$ with a correlation coefficient of 0.72 . Using the terminology of the $k_{e}-\varepsilon$ model, for which the constant $C_{\varepsilon 2}=(n+1) / n$ is defined, it implies in a $C_{\varepsilon 2}=3.7$, which is about 1.7 times greater than the value of the standard model, $C_{\varepsilon 2}=1.92$ (Rodi, 1993). This analysis was conducted to verify the possibility of obtaining statistical parameters linked to the kinetic energy, similar to those found in the literature of turbulence.

\section{Numerical simulations}

\subsection{Introduction}

Turbulence is a three dimensional and time-dependent phenomenon. If Direct Numerical Simulation (DNS) is planned to calculate turbulence, the Navier-Stokes and continuity equations must be used without any simplifications. Since there is no general analytical solution for these equations, a numerical solution which considers all the scales existing in turbulence must use a sufficiently refined mesh. According to the theory of Kolmogorov, it can be shown that the number of degrees of freedom, or points in a discretized space, is of the order of (Landau \& Lifshitz, 1987, p.134):

$$
\left(\mathrm{L}_{\mathrm{k}} / \eta\right)^{3}=\operatorname{Re}^{9 / 4}
$$

where: $L_{k}=$ characteristic dimension of the large-scales of the movement of the fluid, $\eta=$ Kolmogorov micro-scale of turbulence and $\mathrm{Re}=$ Reynolds number of the larger scales. Considering a usual Reynolds number, like $\operatorname{Re}=10^{5}$, the mesh must have about $10^{11}$ elements. This number indicates that it is impossible to perform the wished DNS with the current computers. So, we must lower our level of expectations in relation to our results. A next "lower" level would be to simulate only the large scales (modeling the small scales) or the so called large-eddy simulation (LES). This alternative is still not commonly used in problems composed by a high Reynolds number and large dimensions. So, lowering still more our expectations, the next level would be the full modeling of turbulence, which corresponds to the procedures followed in this study. This chapter presents, thus, results obtained with the aid of turbulence models (all scales are modeled), which is the usual way followed to study flows around large structures and subjected to large Reynolds numbers.

\subsection{Some previous studies}

In recent years an increasing number of papers related to the use of CFD to simulate flows in hydraulic structures and in stepped spillways has been published. Some examples are Chen et al. (2002), Cheng et al. (2004), Inoue (2005), Arantes (2007), Carvalho \& Martins (2009), Bombardelli et al. (2010), Lobosco \& Schulz (2010) and Lobosco et al. (2011). Different aspects of turbulent flows were studied in these simulations, such as the development of boundary layers, the energy dissipation, flow aeration, scale effects, among others. The turbulence models k- $\varepsilon$ and RNG k- $\varepsilon$ were used in most of the mentioned studies, and Arantes (2007) also used the SSG Reynolds stress model (Speziale, Sarkar and Gatski, 1991). Some researchers have still adopted commercial softwares to perform their simulations, such as ANSYS CFX ${ }^{\circledR}$ and Fluent ${ }^{\circledR}$. On the other hand, Lobosco \& Schulz (2010) and Lobosco et al. (2011), for example, used a set of free softwares, among which the OpenFOAM ${ }^{\circledR}$ software. In this study we used the ANSYS CFX ${ }^{\circledR}$ software. 


\subsection{Results}

\subsubsection{Free surface comparisons}

The experiments summarized in Table 1 were also simulated, in order to verify the possibilities of reproducing such flows using CFD. The Exp. 15 is the only one shown here, which main characteristics may be found in Table 1, and which was simulated considering the hypothesis of two-dimensional flow for the geometry sketched in Figure 17a. The inlet velocity was set as the mean measured velocity, with the value of $2.91 \mathrm{~m} / \mathrm{s}$, the outlet boundary condition was set to extrapolate the volume fractions of air and water. The analytical solution presented by Simões et al. (2010) was used to calculate the theoretical profile of the free surface for the single phase flow, for which $f=0.041$ resulted as the adjusted resistance factor. Figure $17 \mathrm{~b}$ contains experimental data and numerical solutions calculated with different meshes and the following turbulence models: zero equation, $\mathrm{k}-\varepsilon$, RNG k- $\varepsilon$ and SSG. These results were obtained combining the non-homogeneous model and the free-surface model for the interfacial transfers. There is excellent agreement between the experimental points, the numerical results and theoretical curve for the one-phase region. It was found that the use of the mesh denoted by M2 (data indicated in the legend) led to results similar to those obtained with the mesh denoted by M1, two times more refined,

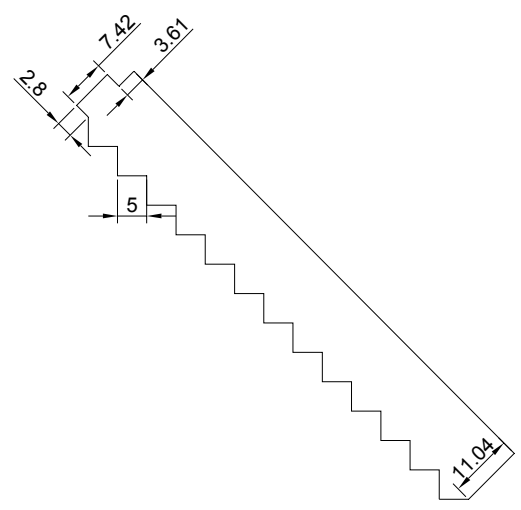

(a)

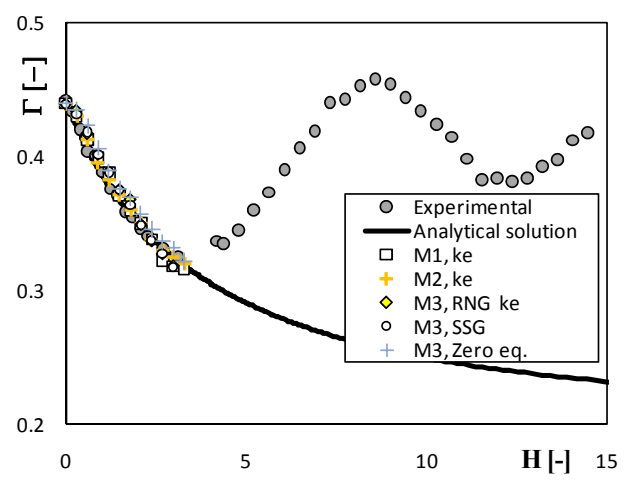

(b)

Fig. 17. Exp. 18 simulations: (a) Geometry and dimensions (in $\mathrm{cm}$ ), (b) Experimental results, numerical solutions and analytical profile $(\mathrm{ke}=\mathrm{k}-\varepsilon ; \mathrm{M} 1$ and $\mathrm{M} 2$ are unstructured meshes with $\sim 0.5 \times 10^{6}$ and $\sim 0.25 \times 10^{6}$ elements, respectively; M3 is a structured mesh with $\sim 0.2 \times 10^{6}$ elements).

when using the k- $\varepsilon$ model. Further, the results obtained with the models RNG k- $\varepsilon$, SSG and without transport equations for turbulence (the three calculated using a third mesh denoted by M3) also superposed well the theoretical solution. In addition to the mentioned turbulence models, also the models k- $\omega$, BSL and k- $\varepsilon$ EARMS were tested. Only the k- $\varepsilon$ EARMS model produced results with quality similar to those shown in Figure $17 \mathrm{~b}$. The k- $\omega$ and BSL models overestimated the depth of the flow, with maximum relative deviations from the experimental values near $8 \%$. The same deviation was observed when using the mixture model in place of the free-surface model (for simulations using the k- $\varepsilon$ model). 
Persistent air cavities below the pseudo-bottom were observed in all simulated results, which is an "uncomfortable" characteristic of the simulations, because the experimental observations did not present such cavities (assuming, as usual, that the numerical solutions converged to the analytical solutions, which, on its turn, is viewed as a good model of the real flows). It must be emphasized that the predictions reproduce the one-phase flow, but that the two-phase flow presents undulating characteristics still not reproduced by numerical simulations. The undulating aspect is observed for different experimental conditions, as shown by Simões et al. (2011), and a complete quantification is still not available.

\subsubsection{Simulations using prototype sizes}

The inhomogeneous model and the k- $\varepsilon$ turbulence model were selected to obtain the freesurface profiles using "numerical" scales compatible with prototype scales. The simulations were performed for steady state turbulence, with $\mathrm{s}=0.60 \mathrm{~m}(27$ simulations $)$ and $\mathrm{s}=2.4 \mathrm{~m}$ (four simulations with $1 \mathrm{~V}: 0.75 \mathrm{H})$, considering two-dimensional domains, using high resolution numerical schemes and applying boundary conditions similar to those already described in the first example. The inlet condition is the same for all simulations (Figure 18a). The angles between the pseudobottom and the horizontal, and the dimensionless parameter $\mathrm{s} / \mathrm{h}_{\mathrm{c}}$, chosen for the simulations were: $53.13^{\circ}\left(0.133 \leq \mathrm{s} / \mathrm{h}_{\mathrm{c}} \leq 0.845\right), 45^{\circ}$ $\left(0.11 \leq \mathrm{s} / \mathrm{h}_{\mathrm{c}} \leq 0.44\right), 30.96^{\circ}\left(0.11 \leq \mathrm{s} / \mathrm{h}_{\mathrm{c}} \leq 0.44\right)$, and $11.31^{\circ}\left(0.133 \leq \mathrm{s} / \mathrm{h}_{\mathrm{c}} \leq 0.44\right)$. For each experiment a numerical value for the resistance factor was calculated, as described in item 4.3.1. Figure $18 \mathrm{~b}$, shows the analytical solution and the points obtained with the Reynolds Averaged

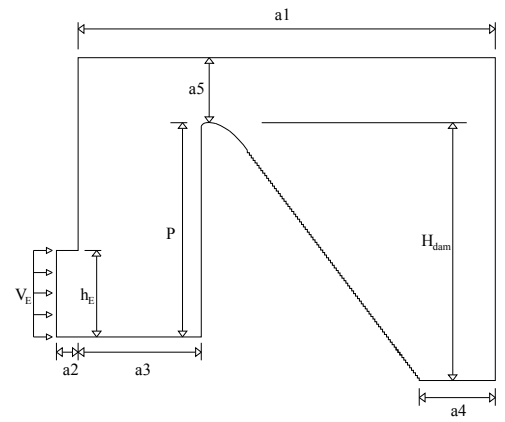

(a)

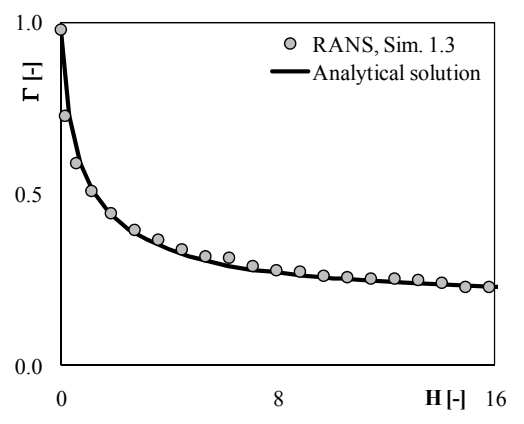

(b)

Fig. 18. (a) Domain employed to perform the simulations for $\alpha=53.13$ (colors $=$ void fraction). The values of $a_{i}(i=1-5), P, H_{d a m}, h_{E}$ were chosen for each test (b) $S_{2}$ profile: numerical and analytical solution.

Navier-Stokes Equations (RANS) for multiphase flows. The axes shown in Figure $18 \mathrm{~b}$ represent the following nondimensional parameters: $\Gamma=h / h_{c}$ and $H=z / h_{c}$. In this case, $z$ has origin at the critical section, where $h=h_{c}$ (close to the crest of the spillway). All the results showed similar or superior quality to that presented in Figure 18.

Figure 19a shows the distribution of the friction factor values obtained numerically, for all simulations performed for the geometrical conditions described in Figure 18a. Figure 19b 
contains the distribution of $\mathrm{f}$ considering the experimental and the numerical data together. It was possible to adjust power laws between $f$ and $k / h_{c}(k=s \cos \alpha)$, in the form $f=a\left(k / h_{c}\right)^{b}$. The values of the adjusted "a" and "b", and the limits of validity of the adjusted equations, together with the geometrical information, are given in Table 2.

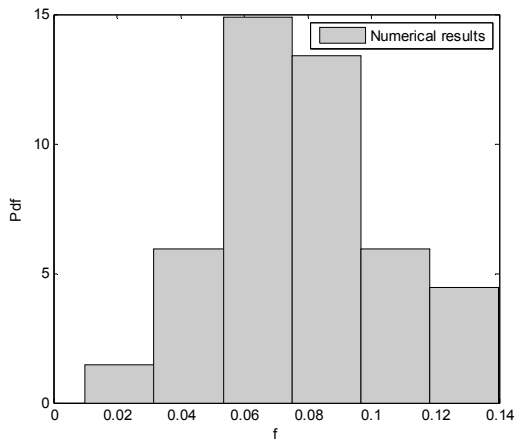

(a)

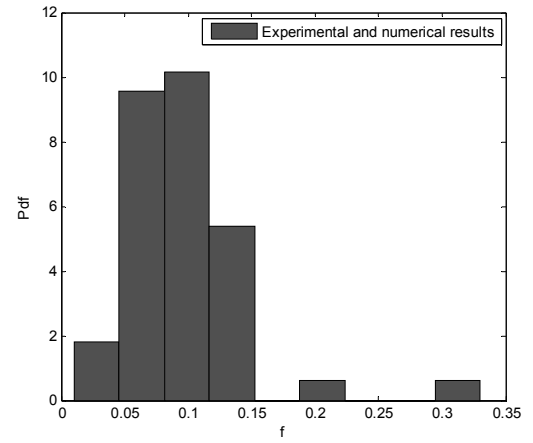

(b)

Fig. 19. Friction factor: (a) Probability distribution function for $11.31^{\circ} \leq \alpha \leq 51.13^{\circ}$ and numerical results; (b) Probability distribution function considering the numerical $\left(11.31^{\circ} \leq \alpha \leq 51.13^{\circ}\right)$ and the experimental results together $\left(\alpha=45^{\circ}\right)$. The total area covered by the bars is equal to 1.0 in both figures $(R=$ correlation coefficient; $R e=4 q / v)$.

\begin{tabular}{cccccc}
\hline$\alpha$ & $\mathrm{a}$ & $\mathrm{b}$ & $\mathrm{k} / \mathrm{h}_{\mathrm{c}}$ & $\mathrm{Re}$ & $\mathrm{R}$ \\
{$[$ degrees $]$} & {$[-]$} & {$[-]$} & {$[-]$} & {$[-]$} & {$[-]$} \\
\hline 53.13 & 0.195 & 0.502 & $0.0798-0.485$ & $8.0 \mathrm{E} 6-1.2 \mathrm{E} 8$ & 0.97 \\
\hline 45.00 & 0.146 & 0.355 & $0.0776-0.311$ & $2.0 \mathrm{E} 7-1.6 \mathrm{E} 8$ & 0.97 \\
\hline 30.96 & 0.185 & 0.294 & $0.0942-0.377$ & $2.0 \mathrm{E} 7-1.6 \mathrm{E} 8$ & 0.96 \\
\hline
\end{tabular}

Table 2. Coefficients for $\mathrm{f}=\mathrm{a}\left(\mathrm{k} / \mathrm{h}_{\mathrm{c}}\right)^{\mathrm{b}}$ and other details.

\section{Conclusions}

In this chapter different aspects of the flows over stepped spillways were described, considering analytical, numerical and experimental points of view. The results show characteristics not usually found in the literature, and point to the need of more studies in this field, considering the practical use of stepped chutes in hydraulic structures. 


\section{Acknowledgements}

The authors thank CNPq(141078/2009-0), CAPES and FAPESP, Brazilian research support institutions, for the financial support of this study.

\section{References}

Arantes, E. J. (2007). Stepped spillways flow characterization using CFD tools. Dr Thesis, School of Engineering at São Carlos, University of São Paulo, São Carlos, Brazil [in Portuguese].

Bauer, W.J. (1954). Turbulent boundary layer on steep slopes. Transactions, ASCE, Vol. 119, Paper 2719, pp. 1212-1232.

Bernoulli, J. (1743). Hydraulics. Dover Publications, 2005.

Boes, R. (2000). Zweiphasenströmung und Energieumsetzung an Grosskaskaden. PhD Thesis - ETH, Zurich.

Boes, R.M. \& Hager, W.H. (2003a). Hydraulic Design of Stepped Spillways. ASCE, Journal of Hydraulic Engineering. v.129, n.9, pp.671-679.

Boes, R.M. \& Hager, W.H. (2003b). Two-Phase flow characteristics of stepped spillways. ASCE, Journal of Hydraulic Engineering. v.129, n.9, p.661-670.

Bombardelli, F.A.; Meireles, I. \& Matos, J. (2010). Laboratory measurements and multi-block numerical simulations of the mean flow and turbulence in the non-aerated skimming flow region of steep stepped spillways. Environ. Fluid Mech., v.11, n.3, pp.263-288. Publisher: Springer Netherlands (DOI 10.1007/s10652-010-9188-6).

Cain, P. \& Wood, I.R. (1981) Instrumentation for aerated flow on spillways. ASCE, Journal of Hydraulic Engineering, Vol. 107, No HY11.

Carosi, G. \& Chanson, H. (2006). Air-water time and length scales in skimming flows on a stepped spillway. Application to the spray characterization. The University of Queensland, Brisbane, Austrália.

Carvalho, R.F. \& Martins, R. (2009). Stepped Spillway with Hydraulic Jumps: Application of a Numerical Model to a Scale Model of a Conceptual Prototype. Journal of Hydraulic Engineering, ASCE 135(7):615-619.

Chamani, M.R. \& Rajaratnam, N. (1999a). Characteristic of skimming flow over stepped spillways. ASCE, Journal of Hydraulic Engineering. v.125, n.4, p.361-368, April.

Chamani, M. R.; Rajaratnam, N. (1999b). Onset of skimming flow on stepped spillways. ASCE, Journal of Hydraulic Engineering. v.125, n.9, p.969-971.

Chanson, H. (1993). Stepped spillway flows and air entrainment. Canadian Journal of Civil Engineering. v.20, n.3, p.422-435, Jun.

Chanson, H. (1994). Hydraulics of nappe flow regime above stepped chutes and spillways. Journal of Hydraulic Research, v.32, n.3, p.445-460, Jan..

Chanson, H. (1996). Air bubble entrainment in free-surface turbulent shear flows. Academic Press, San Diego, California.

Chanson, H. (2002). The hydraulics of stepped chutes and spillways. A.A. Balkema Publishers, ISBN 9058093522, The Netherlands. 
Chen, Q.; Dai, G. \& Liu, H. (2002). Volume of fluid model for turbulence numerical simulation of stepped spillway overflow. Journal of Hydraulic Engineering, ASCE 128(7): pp.683-688.

Cheng X.; Luo L. \& Zhao, W. (2004). Study of aeration in the water flow over stepped spillway. In: Proceedings of the World Water Congress 2004, ASCE, Salt Lake City, UT, USA.

Chow, V.T. (1959). Open channel hydraulics. New York: McGraw-Hill.

Diez-Cascon, J.; Blanco, J.L.; Revilla, J. \& Garcia, R. (1991). Studies on the hydraulic behavior of stepped spillways. Water Power \& Dam Construction, v.43, n.9, p.22-26, Sept..

Frizell, K.H. (2006). Research state-of-the-art and needs for hydraulic design of stepped spillways. Water Resources Researches Laboratory. Denver, Colorado, June.

Hager, W.H. (1995). Cascades, drops and rough channels. In.: Vischer, D.L.; Hager, W.H. (Ed.). Energy dissipators IAHR, Hydraulics Structures Design Manual. v.9, p.151-165, Rotterdam, Netherlands.

Essery, I.T.S. \& Horner, M.W. (1978). The hydraulic design of stepped spillways. 2nd Ed. London: Construction Industry Research and Information Association, CIRIA Report No. 33.

Horner, M.W. (1969). An analysis of flow on cascades of steps. Ph.D. Thesis - Universidade de Birmingham, UK.

Inoue, F.K. (2005). Modelagem matemática em obras hidráulicas. MSc Thesis, Setor de Ciências Tecnológicas da Universidade Federal do Paraná, Curitiba.

Keller, R.J.; Lai, K.K. \& Wood, I.R. (1974). Developing Region in Self-Aerated Flows. Journal of Hydraulic Division, ASCE, 100(HY4), pp. 553-568.

Keller, R.J. \& Rastogi, A.K. (1977). Prediction of flow development on spillway. Journal of Hydraulic Division, ASCE, Vol. 101, No HY9, Proc. Paper 11581, Sept.

Landau, L.D. \& Lifshitz, E.M. (1987). Fluid Mechanics. 2nd Ed. Volume 6 of Course of Theoretical Physics, ISBN 978-0750627672.

Lobosco, R.J. \& Schulz, H.E. (2010). Análise Computacional do Escoamento em Estruturas de Vertedouros em Degraus. Mecanica Computacional, AAMC, Vol. XXIX, No 35, Buenos Aires, http://amcaonline.org.ar/ojs/index.php/mc/article/view/3252, pp.3593-3600.

Lobosco, R.J.; Schulz, H.E.; Brito, R.J.R. \& Simões, A.L.A. (2011). Análise computacional da aeração em escoamentos bifásicos sobre vertedouros em degraus. $6^{\circ}$ Congresso Luso-Moçambicano de Engenharia $/ 3^{\circ}$ Congresso de Engenharia de Moçambique.

Lueker, M.L.; Mohseni, O.; Gulliver, J.S.; Schulz, H.E. \& Christopher, R.A. (2008). The physical model study of the Folsom Dam Auxiliary Spillway System, St. Anthony Falls Lab. Project Report 511. University of Minnesota, Minneapolis, MN.

Matos, J.S.G. (1999). Emulsionamento de ar e dissipação de energia do escoamento em descarregadores em degraus. Research Report, IST, Lisbon, Portugal.

Murzyn, F.\& Chanson, H. (2009) Free-surface fluctuations in hydraulic jumps: Experimental observations. Experimental Thermal and Fluid Science, 33(2009), pp.1055-1064.

Ohtsu, I. \& Yasuda, Y. (1997). Characteristics of flow conditions on stepped channels. In: Biennal Congress, 27, San Francisco, Anais... San Francisco: IAHR, pp. 583-588. 
Ohtsu, I., Yasuda Y., Takahashi, M. (2001). Onset of skimming flow on stepped spillways Discussion. Journal of Hydraulic Engineering. v. 127, p. 522-524. Chamani, M.R.; Rajaratnam, N. ASCE, Journal of Hydraulic Engineering. v. 125, n.9, p.969-971, Sep.

Ohtsu, I.; Yasuda, Y. \& Takahashi, M. (2004). Flows characteristics of skimming flows in stepped channels. ASCE, Journal of Hydraulic Engineering. v.130, n.9, pp.860-869, Sept..

Peterka, A. J. (1953). The effect of entrained air on cavitation pitting. Joint Meeting Paper, IAHR/ASCE, Minneapolis, Minnesota, Aug..

Peyras, L.; Royet, P. \& Degoutte, G. (1992). Flow and energy dissipation over stepped gabion weirs. Journal of Hydraulic Engineering, v.118, n.5, p.707-717, May..

Povh, P.H. (2000). Avaliação da energia residual a jusante de vertedouros em degraus com fluxos em regime skimming flow. [Evaluation of residual energy downstream of stepped spillways in skimming flows]. MSc Thesis. Department of Technology, Federal University of Paraná, Curitiba, Brazil [in Portuguese].

Rajaratnam, N. (1990). Skimming flow in stepped spillways. Journal of Hydraulic Engineering, v.116, n.4, p. 587-591, April.

Richter, J. P. (1883). Scritti letterari di Leonardo da Vinci. Sampson Low, Marston, Searle \& Rivington, Londra. In due parti, p.1198 (volume 2, p.236). Available from <http:// www.archive.org/details/literaryworksofl01leonuoft (16/04/2008).

Rodi, W. (1993). Turbulence Models and Their Application in Hydraulics. IAHR Monographs, Taylor \& Francis, 3a Ed., ISBN-13: 978-9054101505.

Sanagiotto, D.G. (2003). Características do escoamento sobre vertedouros em degraus de declividade $1 \mathrm{~V}: 0.75 \mathrm{H}$ [Flow characteristics in stepped spillways of slope $1 \mathrm{~V}: 0.75 \mathrm{H}$ ]. MSc Thesis. Institute of Hydraulic Research, Federal University of Rio Grande do Sul, Porto Alegre, Brazil, [in Portuguese].

Simões, A.L.A. (2008). Considerations on stepped spillway hydraulics: Nondimensional methodologies for preliminary design. MSc. Thesis. School of Engineering at São Carlos, University of São Paulo, Brazil, [in Portuguese].

Simões, A.L.A. (2011). Escoamentos em canais e vertedores com o fundo em degraus: desenvolvimentos experimentais, teóricos e numéricos. Relatório (Doutorado) Escola de Engenharia de São Carlos - Universidade de São Paulo, 157 pp.

Simões, A.L.A.; Schulz, H.E. \& Porto, R.M. (2010). Stepped and smooth spillways: resistance effects on stilling basin lengths. Journal of Hydraulic Research, Vol.48, No.3, pp.329337.

Simões, A.L.A.; Schulz, H.E. \& Porto, R.M. (2011). Transition length between water and airwater flows on stepped chutes. Computational Methods in Multiphase Flow VI, pp.95-105, doi:10.2495/MPF110081, Kos, Greece.

Sorensen, R.M. (1985). Stepped spillway hydraulic model investigation. Journal of Hydraulic Engineering, v.111, n.12, pp. 1461-1472. December.

Speziale, C.G.; Sarkar, S. \& Gatski, T.B. (1991). Modeling the pressure-strain correlation of turbulence: an invariant dynamical systems approach. Journal of Fluid Mechanics, Vol. 227, pp. 245-272.

Stephenson, D. (1991). Energy dissipation down stepped spillways. Water Power \& Dam Construction, v. 43 , n. 9 , p. 27-30, September. 
Straub, L.G. \& Anderson, A.G. (1958). Experiments on self-aerated flow in open channels. Journal of Hydraulic Division, ASCE Proc., v.87, n.HY7, pp. 1890-1-1890-35.

Tozzi, M.J. (1992). Caracterização/comportamento de escoamentos em vertedouros com paramento em degraus [Characterization of flow behavior in stepped spillways]. Dr Thesis. University of São Paulo, São Paulo, Brazil, [in Portuguese]. 302 pp. Dr Thesis - Universidade de São Paulo, São Paulo.

Wilhelms, S.C. \& Gulliver, J.S. (2005). Bubbles and waves description of self-aerated spillway flow. Journal of Hydraulic Research, Vol. 43, No.5, pp. 522-531. 2005

Wood, I.R.; Ackers, P. \& Loveless, J. (1983). General method for critical point on spillways. Journal of Hydraulic Engineering, Vol. 109, No. 27, pp. 308-312, 1985.

Wood, I.R. (1984). Air entrainment in righ speed flows. Symposium on scale Effects in modelling hydraulic structures, IAHR, Kobus, H. (Ed.), paper 4.1, Sep.. 


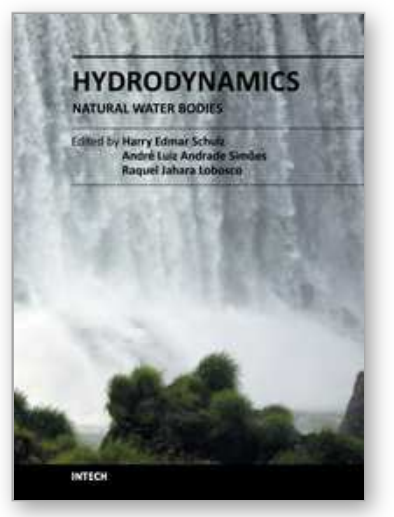

\author{
Hydrodynamics - Natural Water Bodies \\ Edited by Prof. Harry Schulz
}

ISBN 978-953-307-893-9

Hard cover, 286 pages

Publisher InTech

Published online 05, January, 2012

Published in print edition January, 2012

The knowledge of the characteristics of the fluids and their ability to transport substances and physical properties is relevant for us. However, the quantification of the movements of fluids is a complex task, and when considering natural flows, occurring in large scales (rivers, lakes, oceans), this complexity is evidenced. This book presents conclusions about different aspects of flows in natural water bodies, such as the evolution of plumes, the transport of sediments, air-water mixtures, among others. It contains thirteen chapters, organized in four sections: Tidal and Wave Dynamics: Rivers, Lakes and Reservoirs, Tidal and Wave Dynamics: Seas and Oceans, Tidal and Wave Dynamics: Estuaries and Bays, and Multiphase Phenomena: Air-Water Flows and Sediments. The chapters present conceptual arguments, experimental and numerical results, showing practical applications of the methods and tools of Hydrodynamics.

\title{
How to reference
}

In order to correctly reference this scholarly work, feel free to copy and paste the following:

André Luiz Andrade Simões, Harry Edmar Schulz, Raquel Jahara Lobosco and Rodrigo de Melo Porto (2012). Stepped Spillways: Theoretical, Experimental and Numerical Studies, Hydrodynamics - Natural Water Bodies, Prof. Harry Schulz (Ed.), ISBN: 978-953-307-893-9, InTech, Available from:

http://www.intechopen.com/books/hydrodynamics-natural-water-bodies/stepped-spillways-theoreticalexperimental-and-numerical-studies

\section{INTECH}

open science | open minds

\author{
InTech Europe \\ University Campus STeP Ri \\ Slavka Krautzeka 83/A \\ 51000 Rijeka, Croatia \\ Phone: +385 (51) 770447 \\ Fax: +385 (51) 686166 \\ www.intechopen.com
}

\author{
InTech China \\ Unit 405, Office Block, Hotel Equatorial Shanghai \\ No.65, Yan An Road (West), Shanghai, 200040, China \\ 中国上海市延安西路65号上海国际贵都大饭店办公楼 405 单元 \\ Phone: +86-21-62489820 \\ Fax: $+86-21-62489821$
}


(C) 2012 The Author(s). Licensee IntechOpen. This is an open access article distributed under the terms of the Creative Commons Attribution 3.0 License, which permits unrestricted use, distribution, and reproduction in any medium, provided the original work is properly cited. 